\section{AB0229 \\ SHORT-TERM EXPOSURE TO OUTDOOR AIR POLLUTANTS AND RHEUMATOID ARTHRITIS ACTIVITY IN METROPOLITAN AREAS IN THE NORTH OF ITALY}

F. Ingegnoli ${ }^{1,2}$, T. Ubiali ${ }^{1}$, T. Schioppo ${ }^{1,2}$, V. Longo $^{1,2}$, S. lodice $^{2,3}$, E. G. Favalli ${ }^{1}$, O. De Lucia ${ }^{1}$, A. Murgo ${ }^{1}$, V. Bollati ${ }^{2,3}$, R. Caporali ${ }^{1,2},{ }^{1}$ G Pini Hospital, Milan, Italy; ${ }^{2}$ Università degli Studi di Milano, Milan, Italy; ${ }^{3}$ EPIGET Lab, Milan, Italy

Background: Air pollution is believed to cause oxidative stress and systemic inflammation, that could trigger autoimmunity in rheumatoid arthritis (RA). Several epidemiological studies investigated the possible role of air pollution in the outbreak of RA with controversial results. As far as we know, studies on the effects on disease activity of short-term exposure have not been published.

Objectives: To evaluate the impact of short-term exposure to air pollutants (daily mean $\mathrm{PM}_{10}, \mathrm{PM}_{25}, \mathrm{NO}_{2}$ and $\mathrm{O}_{3}$ ) on disease activity in patients with RA.

Methods: Consecutive patients with RA (ACR/EULAR Criteria 2010) resident in Lombardy (Italy) were enrolled. In each patient Disease Activity Score on 28 joints (DAS28), Simple Disease Activity Index (SDAI) were assessed. Daily PM $\mathrm{PM}_{25}, \mathrm{NO}_{2}$ and $\mathrm{O}_{3}$ concentrations, estimated by Regional Environmental Protection Agency at municipality resolution, were used to assign short-term exposure from day of visit back to 14 days. Multivariable linear regression models were performed to identify the day of the pollutants independently associated with disease activity indices, adjusting for the variables significant at the univariate analysis. $\beta$ coefficients were reported for $1 \mathrm{\mu g} / \mathrm{m}^{3}$ increments of pollutants' concentrations. Results: 422 RA patients were enrolled in the study between January and June 2018: $81.5 \%$ females, mean age $58.2 \pm 13.3$ years, mean disease duration $16.1 \pm 11.5$ years, $27.3 \%$ current smokers, $59.5 \%$ RF positivity, $54.5 \%$ ACPA positivity. Sparse punctual statistically significant negative associations emerged at the multivariate analysis between $\mathrm{PM}_{10}, \mathrm{PM}_{25}, \mathrm{NO}_{2}$ and the outcomes, although with very low estimates, whereas positive associations resulted for $\mathrm{O}_{3}$.

Afterwards patients were stratified in 3 subgroups according to their ongoing treatment (no therapy, $n=25$, conventional synthetic Disease Modifying anti-Rheumatic Drugs -DMARDs-, $n=108$ and biological or targeted synthetic DMARDs, $n=289$ ). A statistical significance was found by analysing the influence of therapy on the interaction between $\mathrm{PM}_{2.5}$ and DAS28 (Figure below): a positive trend between $\mathrm{PM}_{25}$ and DAS28 appeared in the first two groups (no therapy, $0.013 \pm 0.007, p=0.06$ and csDMARDs, $0.006 \pm 0.004, p=0.17$ ), whereas a statistically significant inverse association was seen in the b/tsDMARDs group $(-0.005 \pm 0.002, p=0.01)$. Therapy interaction was particularly evident in several days before the visit also for $\mathrm{O}_{3}$.

Estimate for DAS28-CRP (CI 95\%)

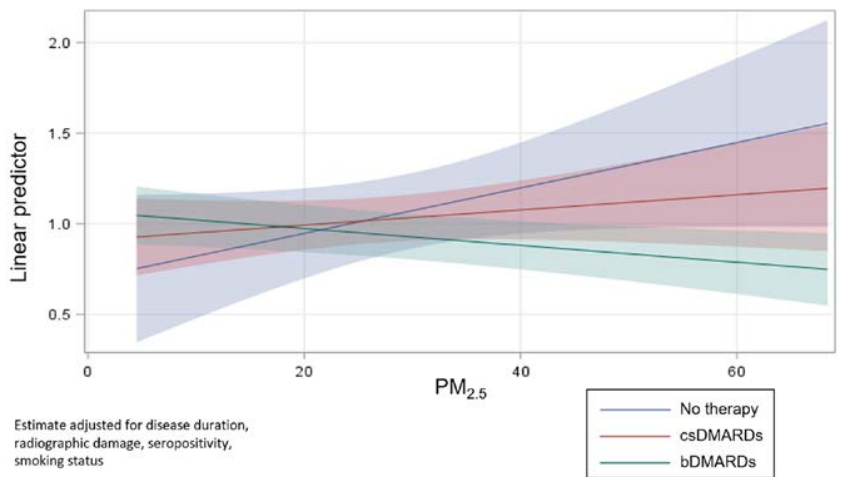

Conclusion: The changes of the outcome measures related to the increase of the pollutants' levels did not reach the minimal clinically important difference, therefore air pollution seems barely relevant on disease activity once the loss of tolerance is established in RA. $\mathrm{O}_{3}$ and $\mathrm{PM} / \mathrm{NO}_{2}$ always exhibit an opposite performance having inversely proportional atmospheric concentrations, whereas the biological role of this substance is still matter of debate and will need further understanding. Therapy seems to be able to interact with the relation between air pollutants and the parameters considered.

Disclosure of Interests: Francesca Ingegnoli: None declared, Tania Ubiali: None declared, Tommaso Schioppo: None declared, Valentina Longo: None declared, Simona lodice: None declared, Ennio Giulio Favalli Consultant of: Consultant and/or speaker for BMS, Eli-Lilly, MSD, UCB, Pfizer, Sanofi-Genzyme, Novartis, and Abbvie, Speakers bureau: Consultant and/or speaker for BMS, Eli-Lilly, MSD, UCB, Pfizer, Sanofi-Genzyme, Novartis, and Abbvie, Orazio De Lucia: None declared, Antonella Murgo: None declared, Valentina Bollati: None declared, Roberto Caporali Consultant of: AbbVie; Gilead Sciences, Inc.; Lilly; Merck Sharp \& Dohme; Celgene; Bristol-Myers Squibb; Pfizer; UCB, Speakers bureau: Abbvie; Bristol-Myers Squibb; Celgene; Lilly; Gilead Sciences, Inc; MSD; Pfizer; Roche; UCB

DOI: 10.1136/annrheumdis-2020-eular.2757

\section{AB0230 STATINS TO PREVENT RHEUMATOID ARTHRITIS: INCONCLUSIVE RESULTS OF THE STAPRA TRIAL}

L. Van Boheemen ${ }^{1}$, S. A. Turk ${ }^{1}$, M. H. Van Beers - Tas ${ }^{1}$, W. H. Bos ${ }^{1}$, D. Marsman ${ }^{2}$, E. N. Griep ${ }^{3}$, M. Starmans ${ }^{4}$, C. D. Popa ${ }^{5,6}$, A. M. Van Sijl ${ }^{1}$, M. Boers ${ }^{1}$, M. Nurmohamed ${ }^{1}$, D. Van Schaardenburg ${ }^{1}{ }^{1}$ Amsterdam UMC | Reade, Amsterdam, Netherlands; ${ }^{2}$ Sint Maartenskliniek, Nijmegen, Netherlands; ${ }^{3}$ Antonius Ziekenhuis, Sneek, Netherlands; ${ }^{4}$ Zuyderland MC, Heerlen, Netherlands; ${ }^{5}$ Bernhoven, Uden, Netherlands; ${ }^{6}$ Radboudumc, Nijmegen, Netherlands

Background: Persons at high risk for developing rheumatoid arthritis (RA) may benefit from a low-risk pharmacological intervention aimed at primary prevention. Statins are safe and widely-used drugs; previous studies demonstrated disease-modifying effects of statins in RA patients ${ }^{1}$ as well as an association between statin use and a decreased risk of RA development ${ }^{2}$.

Objectives: We designed a multi-center, randomized, double-blind, placebo-controlled trial to investigate if atorvastatin use for 3 years could prevent arthritis. Methods: Persons at high risk for RA, defined by the presence of arthralgia and anti-citrullinated protein antibody (ACPA) concentration $>3 x U L N$ or both ACPA and rheumatoid factor (RF), were randomized to atorvastatin $40 \mathrm{mg}$ daily or placebo for 3 years. Eligible participants were $\geq 18$ years, had no indication for lipid-lowering therapy and had no clinical synovitis. The primary endpoint was development of clinical arthritis. Our goal was to include 220 patients, based on an anticipated $30 \%$ risk reduction by atorvastatin. Analysis was by intention-to-treat.

Results: 189 patients were screened, 175 were eligible, but only 67 persons were included of whom 62 were randomized (figure 1). The main reason for non-inclusion was unwillingness to use study medication $(n=58,54 \%)$. Inclusion was stopped after 38 months due to the low inclusion rate. Analyses were performed 1 year after inclusion stop. Mean follow up was 18 (0-36) months. Mean age was 48 years and $74 \%$ of participants were female. 14 persons $(23 \%)$ developed clinical arthritis: $8 / 31$ $(26 \%)$ in the atorvastatin group and 6/31 (19\%) in the placebo group (HR $0.8,95 \%$ Cl 0.3-2.2) after a median period of 7.5 (IQR 5.3-21.8) months (atorvastatin) and 4 (0-14.8) months (placebo). In the atorvastatin group, 17 persons completed the study according to protocol, 6 dropped out and 8 continued follow-up after prematurely stopping study medication. In the placebo group, 16 persons completed the study according to protocol, 11 dropped out and 4 continued follow-up after prematurely stopping study medication. Median duration of study medication use was 9 (6-26) months (atorvastatin group) and 8 (3-17) months (placebo group).

Conclusion: The results of this trial are inconclusive due to severe difficulties with patient inclusion and low treatment adherence. The difficulty to enter and retain participants in this prevention trial is highly relevant given the current interest in treating RA in an ever earlier phase. At-risk individuals' perceptions should be taken into account when designing preventive trials and will be important in optimizing acceptance and adherence to preventive treatment. Currently we are finalizing research into the motivation and barriers for participation in different primary prevention trials of RA and the willingness to initiate different types of preventive treatment in individuals in the at-risk phase of RA.

\section{References:}

[1] McCary et al. Lancet. 2004; 19;363(9426):2015-21

[2] Chodick G et al. PLoS Med. 2010;7(9):e1000336

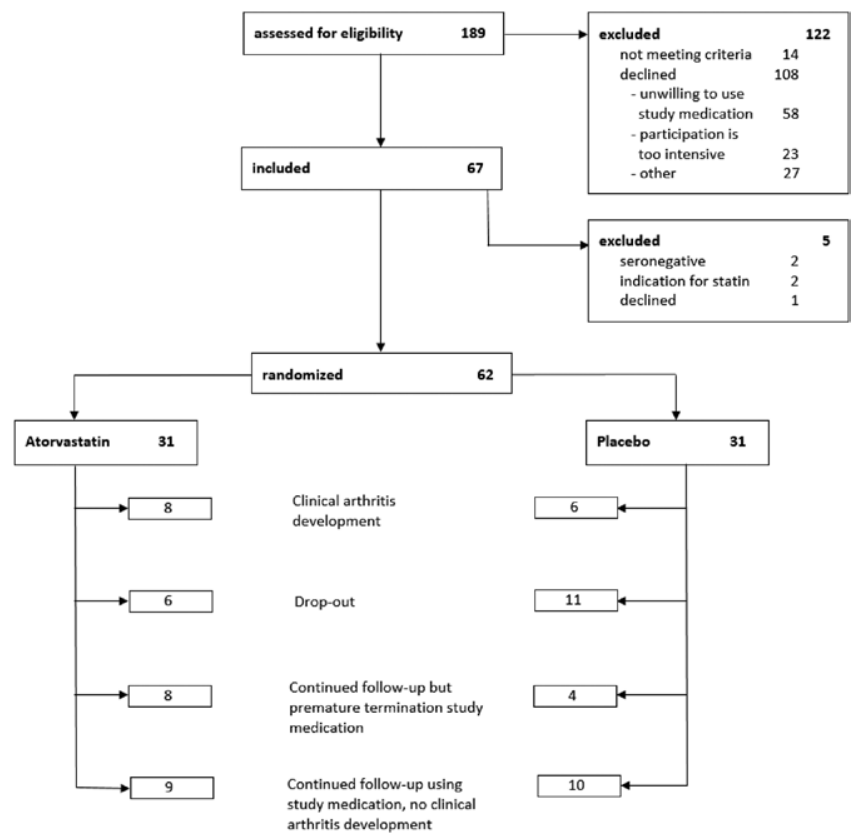


Disclosure of Interests: Laurette van Boheemen: None declared, S.A. Turk: None declared, M.H. van Beers - Tas: None declared, W.H. Bos Grant/research support from: abbvie, sanofi, roche, celgene, ucb, novartis, Speakers bureau: abbvie, Sanofi, eli lilly, Diane Marsman: None declared, E.N. Griep: None declared, M. Starmans: None declared, C.D. Popa: None declared, A.M. van Sijl: None declared, Maarten Boers: None declared, Michael Nurmohamed Grant/ research support from: Not related to this research, Consultant of: Not related to this research, Speakers bureau: Not related to this research, Dirkjan van Schaardenburg: None declared

DOI: 10.1136/annrheumdis-2020-eular.2805

\section{AB0231 \\ RHEUMATOID ARTHRITIS PATIENTS TREATED WITH ABATACEPT AT A COMMUNITY RHEUMATOLOGY CLINIC AND WHO ARE POSITIVE FOR ANTICYCLIC CITRULLINATED PEPTIDE ANTIBODIES HAVE MORE SUSTAINED CLINICAL RESPONSES THAN PATIENTS NEGATIVE FOR THE MARKER}

C. Wiesenhutter ${ }^{1}$, V. Hayden ${ }^{2} .{ }^{1}$ Coeur d'Alene Arthritis Clinic, Coeur d'Alene, United States of America; ${ }^{2}$ Coeur d'Alene Arthritis Clinic, Coeur d"Alene, United States of America

Background: Treating Rheumatoid Arthritis (RA) patients to target (T2T) has been shown to result in better outcomes in patients with RA [1]. There are now a number of therapeutic options to accomplish this goal, but determining which agent to select for each individual has not been defined.

Objectives: The purpose of this post hoc analysis was to assess if Anticyclic Citrullinated Peptide Antibody (anti-CCP) status effects outcomes following treatment of RA patients with Abatacept.

Methods: Patients at a community based rheumatology clinic undergo disease activity measure assessments on a routine basis as part of the implementation of T2T strategy with ongoing assessments on at least a yearly basis. Over the past 15 years there have been 78 patients initiated on treatment with Abatacept at this clinic. Anti-CCP and Rheumatoid factor status is routinely obtained when patients are first seen in the clinic. A patient was considered to be Anti-CCP positive if the test was $20 \mathrm{u} / \mathrm{ml}$ or greater. As a comparison, the 53 patients in the clinic started on Tofacitinib were also analyzed.

The difference in sustained clinical response rates between seropositive and seronegative patients were determined for these two groups. Sustained clinical response was defined as remaining on treatment for at least three years. Patients who were lost to follow up or who died, while on treatment for less than three years, were not included. Statistical analysis was performed with IBM SPSS V. 25 using chi square tests and logistic regression incorporating pretreatment gender, DAS28CRP, CDAI, rheumatoid factor, Multi-biomarker disease activity score, and a power Doppler joint count.

Results: Fifty anti-CCP positive patients and twenty-two anti-CCP negative patients treated with Abatacept were clinically assessed and results of the post hoc analysis are shown in Table one. Chi square risk estimate 4.61 Clinical sig $\mathrm{p}=0.01$. Logistic regression: Unadjusted Risk ratio $(95 \% \mathrm{Cl}) 4.86(1.54,8.18)$ Clinical sig $p=.01$. Adjusted Risk Ratio $(95 \% \mathrm{Cl}) 4.21$ (1.23, 7.19.) Clinical sig $=0.03$.

Results of the post hoc analysis for patients treated with Tofacitinib are shown in Table two. Chi square risk estimate 1.75 (not clinically significant.) Unadjusted Risk 1.70 (not clinically significant). Adjusted Risk 1.42 (not clinically significant).

\begin{tabular}{|c|c|c|c|c|c|}
\hline & & & Responder & & Total \\
\hline & & & yes & no & \\
\hline \multirow[t]{4}{*}{$\mathrm{CCP}$} & ccp positive & Count & 29 & 21 & 50 \\
\hline & & $\%$ within $\mathrm{CCP}$ & $58.0 \%$ & $42.0 \%$ & $100.0 \%$ \\
\hline & ccp negative & Count & 5 & 17 & 22 \\
\hline & & $\%$ within $\mathrm{CCP}$ & $22.7 \%$ & $77.3 \%$ & $100.0 \%$ \\
\hline \multirow[t]{2}{*}{ Total } & & Count & 34 & 38 & 72 \\
\hline & & $\%$ within $\mathrm{CCP}$ & $47.2 \%$ & $52.8 \%$ & $100.0 \%$ \\
\hline
\end{tabular}

Conclusion: Rheumatoid Arthritis patients who are Anti-CCP positive and who are treated with Abatacept in a community rheumatology clinic have a significantly greater number of sustained clinical responses than patients who are Anti-CCP negative.

\begin{tabular}{|c|c|c|c|c|c|}
\hline & & & \multicolumn{2}{|c|}{ Responder } & \multirow[t]{2}{*}{ Total } \\
\hline & & & yes & no & \\
\hline \multirow[t]{4}{*}{$\mathrm{CCP}$} & ccp positive & Count & 21 & 8 & 29 \\
\hline & & $\%$ within $\mathrm{CCP}$ & $72.4 \%$ & $27.6 \%$ & $100.0 \%$ \\
\hline & ccp negative & Count & 9 & 6 & 15 \\
\hline & & $\%$ within $\mathrm{CCP}$ & $60.0 \%$ & $40.0 \%$ & $100.0 \%$ \\
\hline \multirow[t]{2}{*}{ Total } & & Count & 30 & 14 & 44 \\
\hline & & $\%$ within CCP & $68.2 \%$ & $31.8 \%$ & $100.0 \%$ \\
\hline
\end{tabular}

This difference for patients treated with Tofacitinib was not clinically significant in this clinic, though a higher percentage of Anti-CCP positive patients treated with Tofacitinib responded ( $72 \%$ vs $60 \%$ ).

Anti-CCP positivity could be used as a clinical marker to select patients with rheumatoid arthritis to be treated with Abatacept.

References:

[1] Smolen, J. et al. Ann. Rheum Dis 2010:69;638-643

Disclosure of Interests: None declared

DOI: 10.1136/annrheumdis-2020-eular.2223

\section{\begin{tabular}{|l|l}
\hline AB0232 PAIN SCORE WITH VISUAL ANALOG SCALE OF \\
\hline
\end{tabular} 3OMM OR MORE IS A RISK FACTOR OF WORSENING CLINICAL DISEASE ACTIVITY INDEX (CDAI) AT THREE MONTHS AFTER ATTAINING CDAI REMISSION IN PATIENT WITH RHEUMATOID ARTHRITIS}

I. Yoshii ${ }^{1}{ }^{1}$ Yoshii Hospital, Rheumatology and Musculoskeletal Medicineo, Shimanto City, Japan

Background: In treating with rheumatoid arthritis (RA), it is needless to say essential treatment goal with first priority. On the other hand, patient's pain influences on clinical indices deeply, however, pain score is not been regarded as most important despite that correlates with patient reported outcome.

Objectives: Clinical significance of remnant pain score for clinical outcome although attaining remission in clinical disease activity index (CDAI) statistically.

Methods: RA patient who have attained remission with CDAl were picked up. These patients were divided into two groups whether CDAl at three month after the first CDAI remission attained; namely CDAI-R or CDAI-F. Background data such as sex, age at onset, age, anti-cyclic citrullinated polypeptide antibodies (ACPA), rheumatoid factor (RF), Sharp/van der Heijde Score (SHS), clinical disease activity score (CDAI), C-reactive protein (CRP), modified Health Assessment Questionnaire score ( $\mathrm{mHAQ}$ ), and pain score with visual analog scale (PS-VAS) at first consultation, time span from the first consultation to first CDAl remission were compared between the two groups using Mann-Whitney U-test. CDAI, CRP, mHAQ, PS-VAS, and QOL value calculated from EuroQOL-5 dimension questionnaire $(E Q-5 D)$ at the time of CDAl were also statistically compared with Mann-Whitney U-test. Parameters that demonstrated statistical significance within $5 \%$ were picked up, and odds ratio for CDAI remission were calculated with binary logistic regression analysis. Moreover, parameters that demonstrated statistical significance with $p$-value within $5 \%$ were evaluated with receiver's observational characteristics $(\mathrm{ROC})$ analysis, and cut-off index (COI) was calculated.

Results: A total of 907 patients with 594 CDAI-R and $313 \mathrm{CAI}-\mathrm{F}$ were recruied. Demographic characteristics of the two groups were shown in Table 1. SHS at first consultation and time span from first consultation to CDAl remission attained demonstrated significantly less in the CDAI-R than the CDAI-F group, while the other parameters demonstrated no significant difference. CRP, CDAI, $\mathrm{mHAQ}, \mathrm{PS}-\mathrm{VAS}$, and QOL at CDAI remission demonstrated significant difference between the CDAI-R and CDAI-F groups. With binary logistic regression analysis, CRP, CDAl, and PS-VAS demonstrated significant regression for CDAI-R with $1.68,0.71$, and 0.78 in odds ratio, respectively. COI for CDAI remission was $0.4,1.0$, and 30 for CRP $\left(p=2.4 \times 10^{-4}\right)$, CDAI $\left(p=3.0 \times 10^{-32}\right)$, and PS-VAS $(p=2.4$ x $10^{-4}$ ), respectively.

Conclusion: PS-VAS at the moment of CDAI remission is suggested to be predictive factor for sustaining CDAI remission at three months thereafter as well as CRP value and the CDAI score. 